\title{
Five Common Mistakes for Using Partial Least Squares Path Modeling (PLS-PM) in Management Research
}

\author{
Asyraf Afthanorhan \\ Faculty of Business and Management, University Sultan Zainal Abidin, \\ Kampus Gong Badak, Malaysia \\ E-mail: asyrafafthanorhan@unisza.edu.my \\ Zainudin Awang \\ Faculty of Business and Management, University Sultan Zainal Abidin, \\ Kampus Gong Badak, Malaysia \\ E-mail: zainudinawang@unisza.edu.my
}

Nazim Aimran

Advanced Analytics Engineering Centre, Faculty of Computer and Mathematical Sciences, Universiti Teknologi MARA, Malaysia

E-mail: ahmadnazim@uitm.edu.my

\begin{abstract}
The value of Partial Least Squares Path Modeling (PLS-PM) in management research has now been acknowledged, although the PLS-PM was developed for a reason. First, the PLS-PM was developed as an alternative to Covariance based Structural Equation Modeling (CBSEM) when exploratory research is conducted. As far as this method concerned, many researchers are misused or overuse the application of PLS-PM without understanding the basic knowledge in structural equation modeling. Thus, the purpose of this paper is to discuss the five common mistakes (data distributions, sample size limitations, unsatisfactory fitness index, misunderstanding between confirmatory and exploratory research, and poor factor loadings) for using PLS-PM over CB-SEM in management research. We concluded that the researchers should respect these methods and justify their use when conducting the research projects because some of the projects might be better for CB-SEM or PLS-PM.
\end{abstract}

Keywords: PLS-PM, CBSEM, Exploratory research, Structural Equation Modeling 


\section{INTRODUCTION}

In the past few years, the marketing and management research has been a substantive increase in the number of submissions, dissertations, journals, and publications using Partial Least Square Path Modeling (PLS-PM) techniques (Aimran et al., 2017; Afthanorhan et al., 2018) as displayed in Figure 1. In this analysis, we included keywords related to PLS-PM to better understand the substantive research topic of interest. This recent increase might be due to the increasing number of friendly statistical packages such as SmartPLS, PLS Gui SaaS, WarpPLS, VisualPLS, XLSTATPLS, SPADPLS, Adanco, and PLS Graph. Another reason could be the increased relevant resources explaining its application, such as Hair et al. (2019), Ghasemy et al. (2020), and Ringle et al. (2019).

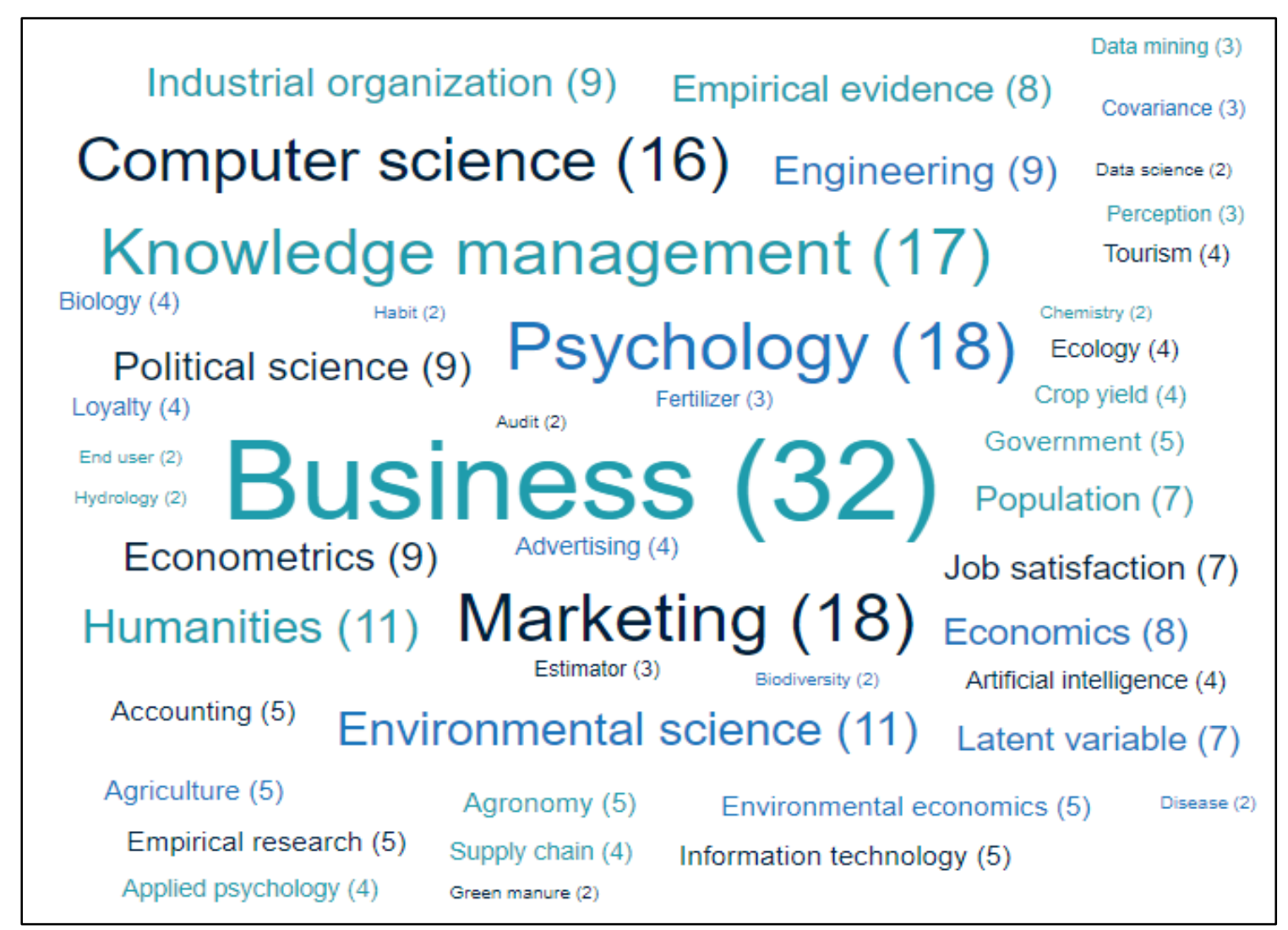

Figure 1 Word Cloud of the Keyword of the Top Field Using PLS-PM

The PLS-PM was also recognized as the composite factor method as the method generates the parameter estimates from the linear combination of manifest variables in the construct. In contrast, the Covariance Based Structural Equation Modeling (CBSEM) that exemplified in several statistical packages such as AMOS, LISREL, Mplus, EQS, and Lavaan known as the common factor method. Both of them are differently used, as depicted in Table 1. Dijkstra \& Henseler (2015) reported that PLS- 
PM was declared as the most prominent approach among the composite factor method because it can assist the applied researchers to handle complex modeling without the presence of stringent assumption which contradicts what CBSEM has (Zainol et al., 2019; Afthanorhan et al., 2019).

Table 1 Common Factor and Composite Factor Method

\begin{tabular}{|c|c|}
\hline Common Factor Method & Composite Factor Method \\
\hline $\begin{array}{l}\text { Maximum Likelihood-based } \\
\text { CBSEM (ML-CBSEM) }\end{array}$ & $\begin{array}{l}\text { Partial Least Squares Path } \\
\text { Modeling (PLS-PM) }\end{array}$ \\
\hline $\begin{array}{l}\text { Diagonal Weighted Least Squares } \\
\text { (DWLS-CBSEM) }\end{array}$ & $\begin{array}{c}\text { Generalized Structure Component } \\
\text { Analysis (GSCA) }\end{array}$ \\
\hline $\begin{array}{l}\text { Weighted Least Squares Maximum } \\
\text { Variance (WLSMV-CBSEM) }\end{array}$ & Consistent PLS (PLSc) \\
\hline $\begin{array}{l}\text { Asymptotic Distribution Free } \\
\text { (ADF-CBSEM) }\end{array}$ & Weighted PLS \\
\hline $\begin{array}{l}\text { Generalized Least Squares (GLS- } \\
\text { CBSEM }\end{array}$ & PLS Predict \\
\hline \multicolumn{2}{|c|}{ Statistical Software } \\
\hline AMOS & SmartPLS \\
\hline LISREL & ADANCO \\
\hline MPLUS & Warp PLS \\
\hline LAVAAN & PLS Graph \\
\hline EQS & PLS Gui \\
\hline
\end{tabular}

In the historical roots, PLS-PM was formulated by Herman Wold in 1982 that is recognized as an alternative to the CBSEM method (Wold, 2004). This, however, PLSPM was viewed as not appropriate for statistical tools in empirical research as it has serious implications for model specifications, absence of measurement error, biasedness of indicator loadings and weight, biasedness of construct correlation, lacking global fitness index, and improper solution to bootstrapping techniques (Antonakis et al., 2010; Vandenberg, 2006; Ronkko \& Evermann, 2013; Aguirre-Urreta \& Marakas, 2014; Mcintosh et al., 2014; Goodhue, Lewis \& Thompson, 2012; Aguirre-Urreta \& Ronkko, 2018). Such previous researches are addressed allegedly insurmountable flaws associated with the use of PLS-PM and go so far as to explicitly and implicitly call for a ban and condemn their use.

Nevertheless, Lohmoller (1989) and Henseler, Hubona, \& Ray (2016) claimed that PLS-PM remains relevant if the study is accompanying with exploratory purpose or 
misspecification of the measurement model. The misspecification measurement model can be identified if the applied researchers are not sure about the causal effect between exogenous and endogenous constructs. The exploratory purpose is defined if the applied researchers are not having possible literature theories or evidence to support the model proposed. More precisely, the PLS-PM was proper for predicting rather than estimating the relationships between latent variables or construct in a hypothesized model. Although PLS-PM was known for exploratory purpose since its inception yet, some of the applied researchers elucidated that PLS-PM can fix with the confirmatory or exploratory purpose (Ringle et al., 2018; Sarstedt et al., 2016; Schuberth, Henseler, \& Dijkstra, 2018). Throughout their discussions, the method of PLS-PM is apparently accepted in many journals or publications for confirmatory purposes as it uses an established theory for testing.

Since then, the debate on the true nature of PLS-PM was endless, specifically on statistical methodologies. Unfortunately, articles on statistical flaws within PLS-PM are not considered seriously, and its usefulness is repeatability used in all situations. To be clear, many applied researchers were overuse PLS-PM in management research. The applied researcher should bear in mind that there are a time and place for PLS-PM or CBSEM that we can use for data analysis. For this example, there are times in which PLS-PM is can or cannot be applied in management research rather than encouraging it to be a method of choice in various domains. Therefore, it would be better if the applied researchers can understand the concept of PLS-PM and know when it can be used to examine a research model.

In other words, the researchers are just as lackadaisical about selecting the appropriate approach in SEM as they seem inclined to handle less stringent assumptions. Compared with standard CBSEM, the statistical assumptions are even more complicated as the Maximum Likelihood estimator is always preferred. As such, the applied researcher's opined PLS-PM indeed was a 'silver bullet' method without an attempt to understand the statistical underpinnings. The intractable publications using PLS-PM are actually questionable because the estimates yielded from that analysis may not be compatible with the model proposed as PLS-PM naturally developed for exploratory sense. Consequently, one can be sure that many publications in the confirmatory sense with PLS-PM are improper solutions which mean most of the previous findings was not meet the current dynamics progress. With this consistent thinking, Dijkstra \& Henseler (2015) consent to label PLS-PM under exploratory sense. They admitted PLS-PM technique could not be relevant for confirmatory studies, but it can be appropriate if the factor correlations are corrected. Thus, they introduced new coefficient reliability in the conjunction of PLS-PM to provide consistent path coefficients and indicator loadings that are seemed suitable for confirmatory studies. 
The impressive development in PLS-PM, so-called Consistent Partial Least Square (PLSc), was declared more powerful than PLS-PM (Dijkstra \& Scmerlleh-engel, 2014).

Although PLSc is maybe better than PLS-PM, yet, the improvement in the conjunction of PLS algorithm associated with factor correlations just manages to produce consistent estimates and indicator loadings that are always debated for many ages. In fact, there are more other statistical flaws present in its application that are still unresolved. Thus, it is too early to note PLSc tenable as CBSEM to accommodate well in the confirmatory approach that seeks accurate estimates of one variable's effects on another variable (Bollen \& Diamantopoulos, 2017). To be part of the confirmatory approach, the method adopted should comply with several statistical assumptions so that the results produced are not harmed (improper solutions). In particular, the procedures related to the confirmatory approach must take into account the measurement error, measurement effect, consistent indicator loadings, consistent factor correlations, global fit indexes, disturbance of the endogenous variables, and high statistical power (tended to reject poor models). Among these, PLSc is lags far behind those of CBSEM in many perspectives.

Turning back to the discussion on PLS-PM, more researchers believe PLS-PM was capable as CBSEM to adapt well as a confirmatory approach. Yet, this faithful is contravene with the recent seminal work by Dijkstra \& Henseler (2015). Accordingly, PLS-PM was only relevant if the models were classified under exploratory sense, and PLSc is superior to accommodate both characters, whether in the exploratory or confirmatory sense. Yet, the interpretation confounding within PLS-PM in behavioral sciences has remained unclear. Instead, this is not a good time to propose PLSc technique if the controversy relies upon PLS-PM was kept abandoned. Therefore, it is a serious problem if the researchers are continuously misused structural equation models in the research methodology. Align with this background, the purpose of the present article is to address each possible situation that leads the researchers to adopt PLS-PM technique. Our ultimate aim is to advance our understanding to the readers of which situations are necessary for PLS-PM technique so that results revealed for managerial decisions are valid.

\section{Foundation of PLS-PM}

Historically, PLS-PM was developed as an alternative to CBSEM when the study related is too complicated and lacks literature theories (Fornell \& Bookstein, 1982). Herman Wold introduced it in the early of 1970, but its inception was debated due to some limitations applied in PLS-PM. Nevertheless, its performance has been improved in the early 2000 by the proponent of PLS-PM, as shown in Figure 1. 


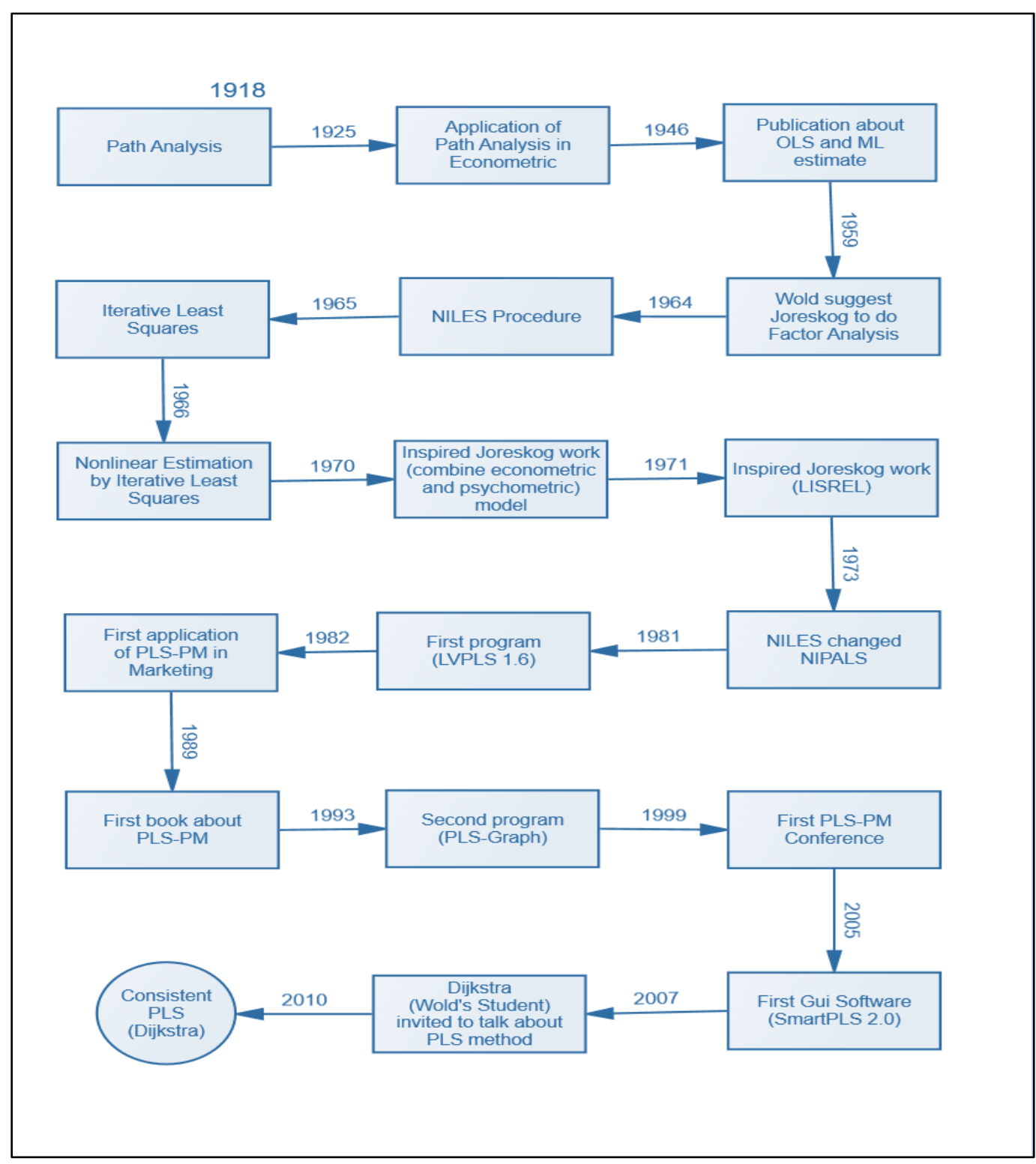

Figure 1 Development of PLS-PM

To be clear, PLS analysis can be viewed as one of the composite approaches that adopt one strategy of estimating a latent variable as a component or weighted composite of indicators (Takane \& Hwang, 2017; Hwang, Takane, \& Tenenhaus, 2015). In contrast, the established method as CBSEM adopts a strategy of estimating a latent variable as a common factor of indicators (Bollen, 2011; Bollen \& Noble, 2011). In this regard, PLS-PM can be considered a composite-based structural equation modeling. Meanwhile, CBSEM can be trusted as a common factor-based structural equation modeling.

Composite-based structural equation modeling actually has three known approaches: regression on sum scales, generalized structured component analysis, and 
PLS analysis. All of these approaches using a limited information estimator (e.g., ordinary least square) to obtain the path coefficient and indicator loadings with the help of the iterative algorithm to minimize the criterion function. Among these approaches, only PLS analysis needs two steps which called internal (component with indicators) and external (causal between latent variables) estimation that is prior to estimating the path coefficients (Hwang, Takane, Tenenhaus, 2015; Ronkko, McIntosh \& Antonakis, 2015; Ronkko et al., 2016). It was believed composite is the only rationale for the exploratory purpose because PLS (composite approach) estimates a more general model than CBSEM and is less affected by model misspecification or poor model in some parts of the model. Basically, the estimates obtained were meaningless if the common factor model was incorrectly, and thus the common factor is always viewed as a confirmatory tool (Antonakis et al., 2010). Furthermore, the composite factor model relaxes the strong assumption that all the covariation between the manifest variables' block is explained by a common factor method (Henseler, Ringle, \& Sarstedt, 2015). This means that the composite factor does not impose any restrictions on the covariance between manifest variables of the same latent variables. Therefore, PLS-PM has advantages over CBSEM to handle non-normal data, fewer indicators per construct, possible to include a larger number of indicators, assumes all measured variance is useful for prediction, small sample size, and fitness index is not determined.

With this regard, most the applied researchers are interested in PLS-PM attractiveness since its inception. Compared with standard CBSEM, the researchers must conduct the path analysis and confirmatory factor analysis independently to make the estimates derived reliable. To do so, researchers face the difficulty to fix the latent variables constitute under CBSEM. That is, the interpretation model must be include model testing, model validation, and model fit. All of these models are prior to achieving each construct's validity, and it is only can be presented with CBSEM.

Furthermore, global fit statistics nested in CBSEM are aimed to measure the magnitude of indicators loadings and other model parameters in a complementary fashion when assessing the measurement models. Such models do not exist in PLS-PM, which is why PLS-PM was considered an exploratory tool since it is much more flexible than CBSEM. This point may illustrate that the PLS-PM is prioritized for the exploratory approach only. As mentioned earlier, the study aims to describe what possible situations that encourage the applied researchers to elect PLS-PM rather than CBSEM.

\section{Fundamental of PLS-PM}


For the management research, these updated methodologies achievement in PLSPM can benefit the applied researchers as it can model the nomological network by expressing the relationships between constructs in a single research model. According to Hair et al. (2019) and Sarstedt et al. (2020), the PLS-PM was the full-fledged method that has many advantages over the CBSEM. These advantages are shown in the following table about PLS-PM properties.

Table 2 PLS-PM Properties

\begin{tabular}{|c|c|c|}
\hline No. & Condition & Explanation \\
\hline 1. & Sample size requirement & $\begin{array}{l}\text { According to Chin (1999), PLS-PM can } \\
\text { handle at least } 20 \text { sample sizes. Generally, } \\
\text { the PLS-PM can achieve a high level of } \\
\text { statistical power with small samples }\end{array}$ \\
\hline 2. & Data distribution & $\begin{array}{l}\text { No distributional assumptions are needed. } \\
\text { Thus, PLS-PM method works well with } \\
\text { non-normal data distributed. }\end{array}$ \\
\hline 3. & Measurement scale & $\begin{array}{l}\text { PLS-PM can work with a categorical and } \\
\text { continuous scale }\end{array}$ \\
\hline 4. & Number of items per construct & $\begin{array}{l}\text { PLS-PM easily handle more than } 50 \text { items } \\
\text { per construct as the method can generate } \\
\text { the latent variable score for estimation } \\
\text { purpose. }\end{array}$ \\
\hline 5. & Model conceptualization & $\begin{array}{l}\text { PLS-PM easily incorporates formative and } \\
\text { reflective construct simultaneously }\end{array}$ \\
\hline 6. & Model complexity & $\begin{array}{l}\text { Can handle complex model with many } \\
\text { structural relationships and items per } \\
\text { construct. }\end{array}$ \\
\hline 7. & Model identification & $\begin{array}{l}\text { PLS-PM does not have model } \\
\text { identification to generate the parameter } \\
\text { estimates }\end{array}$ \\
\hline 8. & $\begin{array}{l}\text { Measurement model } \\
\text { assessment }\end{array}$ & $\begin{array}{l}\text { PLS-PM has a limited number of global } \\
\text { fitness index and can delete many items }\end{array}$ \\
\hline 9. & Structural model assessment & $\begin{array}{l}\text { PLS-PM provides the predictive relevance } \\
\left(\mathrm{Q}^{2}\right) \text { and effect size }\left(\mathrm{f}^{2}\right) \text { result for the } \\
\text { targeted construct }\end{array}$ \\
\hline 10. & Efficiency & $\begin{array}{l}\text { The results can be obtained after a few } \\
\text { iterations. }\end{array}$ \\
\hline
\end{tabular}




\section{REVIEW ON THE CRITICAL SITUATION WHEN APPLYING PLS-PM}

\section{Mistake 1: Data Distribution}

PLS-PM was always perceived as the best choice in structural equation models when the researchers have to deal with non-normal data. Because PLS-PM was developed on the basis of the non-parametric assumption that is no stringent assumption is necessary for estimating the path coefficient of the structural model. Consequently, the applied researchers believe adopting PLS-PM is not a serious issue in the research methodology in that it is well developed to control multiple variables concurrently. This belief should not be allowed in the quantitative methodology. Because every method developed actually has its own objective and purpose of assuring the research requirement can be satisfied. The main reason PLS-PM is flexible than those of CBSEM was induced the ordinary least square estimator is utilized to derive the path coefficients of measurement and structural model. That estimator relaxes the strong covariation between blocks of indicator that cannot be visualized in the model (Henseler, Hubona, \& Ray, 2016). As such, the PLS-PM was viewed as a composite factor method that is appropriate for exploratory sense.

In the previous research, most of the published paper debunks that CBSEM is one of the parametric approaches that is the normality data should be considered in the first place. In order to make sure the statistical assumptions that constitute under CBSEM is achieved, they assure the normality data can be maintained. In fact, there are more simulation study believe CBSEM is totally robust against the departure of normality. It can be verified by Bollen (1989) and Jöreskog \& Sörbom (1989) through their simulation studies based on non-normal data. Furthers, Yuan \& Bentler (1998) contend that maximum likelihood estimator-based structural equation modeling is able to yield consistent path coefficients of the structural model from the minimum sample size of 50. The problem here is that the outcome of standard error cannot be conserved, and thus the supplementary approach is necessary as the bootstrap approach accompanies a maximum likelihood estimator to stabilize the standard error. Thereby, the existence of non-normal data can actually be remedied by applying those approaches to ensure the path coefficients of the structural model are proper.

Other than that, the researchers can attempt another estimator such as asymptotic distribution-free, which is the requirement for normal data was neglected. Because asymptotic distribution-free was not part of Consistent Asymptotic Normality (CAN), that is the normality assumption is prior to the best fit for path coefficient of structural 
model (Anderson \& Gerbing, 1988). It can be inferred that traditional structural equation modeling is actually able to handle both types of normal and non-normal.

\section{Mistake 2: Sample Size Limitation}

The sample size requirement for structural equation modeling was frequently one of the problematic issues for many ages. Because there is more recent literature that decides the minimum requirement for sample size, the minimum sample size required should be more than 100 of sample size (Hoyle, 1995; Byrne, 2016; Aziz et al., 2019). Accordingly, those sample size was tailored to the nature of structural equation modeling to ensure the result revealed represents the actual population. Other than that, it can help the analyst to resort to structural equation modeling produce findings free from the presence of improper solutions and non-convergence of path coefficients (Anderson \& Gerbing, 1988; Marsh, Wen, \& Hau, 2004; Fan, Thompson \& Wang, 1999; Chen et al., 2001). Furthers, some of the literature affirmed that the size of the model (number of indicator per factor) influence the effects of estimation method (Ding, Velicir, \& Harlow, 1995; Kline, 2015; Loehlin, 1998; Marsh, Hau \& Balla, 1998) and it was believe become one of the common practice lately for those whom interest to structural equation modeling as their resolution. Thereby, an unreasonable sample size (below than 100 of sample size) resulting in the researchers leading to another convenience approach that is not necessary for high samples.

As such, the PLS-PM may be preferable to those of CB-SEM if the researchers deal with such insufficient sample size when testing the relationship between latent variables. For researchers, obtaining high samples may provide a great challenge, specifically when their research scope was restricted. For these reasons, the researchers believe PLS-PM is prioritized over CBSEM. The simulation studies verify that PLSPM is superior under conditions of small sample size and violation of data distribution (Chin et al., 2003; Haenlein \& Kaplan, 2004) where the estimation of the structural model is unaffected, which means remain proper solutions for decision.

Although PLS-PM seemed better than CBSEM in terms of the sample size perspective, the estimation method remains as the composite factor, which means the result derived is acceptable under exploratory sense only (see Goodhue, Lewis \& Thompson, 2006 for distinguishing between common factor and composite factor). Other than that, the model specified was invalid and cannot proceed with testing the hypothesized model. Moreover, the PLS-PM was touted as able to handle the complex relationships as sample size as 20 (Chin \& Newstedt, 1999), and it is the reason what leads the researchers to choose PLS-PM over CBSEM when it comes to the small samples. 
The reason for choosing PLS-PM when involves a small sample is prohibited as the estimation method was actually developed, not resolving the sample issue. In statistics underpinning, population sampling is the process of a select subset of subjects or respondents that is representative of the entire population (Polkinghorne, 2005). The estimation obtained based on population sampling must be reflected with the actual population to ensure the real estimates are worth the research. To ensure such estimation is worthy, the sufficient sample size is necessary for statistical methodologies that involve a structural equation model approach.

The structural equation modeling approach for small sample size and the sample's minimum requirement remains questionable, although more studies discuss this issue (Herzog \& Boomsma, 2009; Lai \& Kelley, 2011; Bentler \& Yuan, 1999). It is because of using the maximum likelihood estimator as one of the preferable estimators limiting the ability of structural equation modeling. Therefore, the best solution for small samples is to collect sufficient data and ensure the variable involves in the model has high quality. The researchers may adopt a strategy of enhancing items' quality through Item Response Theory (IRT; Embretson \& Reise, 2013; Lord \& Wingersky,1984; van der Linden \& Hambleton, 2013) in the first place before subsequent to the analysis phase. On another typical occasion, the researchers may delete low-quality variables by scrutiny their value of factor loadings as recommended by Hair et al. (2019). Accordingly, the strength of factor loading is differ depending on the sample size requirement. Apart from that, the use of item parceling in the model may be beneficial for this situation since the sample size requirement is tied to the model's size (Landis, Beal, \& Tesluk, 2000; Ronkko \& Evermann, 2013). One conclusion can be made that the issue of sample size in the handling of structural equation modeling should be discontinued. Thus, such a plea is not admissible for researchers to switch to PLS-PM. 
Table 3 Significance Factor Loading based on Sample Size

\begin{tabular}{|c|c|}
\hline Factor Loading & Sample Size needed for Significance \\
\hline 0.30 & 350 \\
\hline 0.35 & 250 \\
\hline 0.40 & 200 \\
\hline 0.45 & 150 \\
\hline 0.50 & 120 \\
\hline 0.55 & 100 \\
\hline 0.60 & 85 \\
\hline 0.65 & 70 \\
\hline 0.70 & 60 \\
\hline 0.75 & 50 \\
\hline
\end{tabular}

Source: Hair et al. (2019)

\section{Mistake 3: Unsatisfactory of fitness index}

In structural equation modeling practice, the fitness model should be reported to reflect on how well the model being researched. It can be identified with the fitness index such as Chi-square normalized by degree of freedom (Chisq/df), Root Mean Square Error Approximation (RMSEA), Comparative Fit Index (CFI), Incremental Fit Index (IFI), Tucker-Lewis Index (TLI), and Normed Fit Index (NFI) as shown in Table 4. All of this fitness should be complying with the threshold values as it believes capable of identifying a misspecified model that cannot be proven by PLS-PM (McIntosh et al., 2014). To ensure the model can be tested with the covariance-based structural equation model, the researcher must confirm the fitness model through Confirmatory Factor Analysis (CFA). The CFA can be driven by two measurement models such as individual measurement and pooled measurement model. Among these, the pooled measurement model is much better than the other ones as it can take account of two indicators per factor and latent variable correlations (Chong, Nazim, \& Ahmad, 2014).

This, however, the fitness index may not be completely satisfied when the researchers utilize the CFA technique. Because the required level for each fitness index is excessively high for research requirement as the parsimonious index (Chisq/df < 3.0), absolute index (RMSEA < 0.08), and incremental index (CFI, IFI, TLI, NFI > 0.90). Generally, the model may have jeopardized if the model involves a great number of size variables and latent variables (Hair et al., 2017). Therefore, the measurement model's unsatisfactory fitness index can be one of the primer substances that pushes the researchers to move on to the other approach as PLS-PM that compromises with great help. Theoretically, the common factor adopted in the covariance structural equation 
model entails one of the strong literature and evidence, which means the model must be truly established. Apart from that, common method bias may affect the measurement fitness as the questionnaire was not familiar with the study's scope. Therefore, the assessment for common method bias becomes an interesting method to ascertain the applied researchers detecting the item problem. So far, there are three approaches available for examining the method bias, namely Harman Single-factor, common latent factor, and marker variables. Among them, Harman single factor is the most prominent technique across the field as it is very convenient and understandable. Thus, avoiding CB-SEM use due to improper fitness is not compromising the results for hypothesis testing can be trusted. Because selecting the wrong method for data analysis can lead to the wrong conclusions.

Table 4 Fitness Indexes

\begin{tabular}{|l|l|c|}
\hline \multicolumn{1}{|c|}{ Categories } & \multicolumn{1}{|c|}{ Fitness Index } & $\begin{array}{c}\text { Recommended } \\
\text { values }\end{array}$ \\
\hline Absolute Fit Index & Chi-square & P >0.05 \\
\cline { 2 - 3 } & $\begin{array}{l}\text { Root Mean Square Error } \\
\text { Approximation (RMSEA) }\end{array}$ & $<0.08$ \\
\cline { 2 - 3 } & Goodness of Fit & $>0.90$ \\
\hline Incremental Fit Index & Adjusted Goodness of Fit (AGFI) & $>0.90$ \\
\cline { 2 - 3 } & Comparative Fit Index (CFI) & $>0.90$ \\
\cline { 2 - 3 } & Tucker-Lewis Index (TLI) & $>0.90$ \\
\cline { 2 - 3 } & Normed Fit Index (NFI) & $<5.90$ \\
\hline \multirow{2}{*}{$\begin{array}{l}\text { Parsimonious Fit } \\
\text { Index }\end{array}$} & Chi-square/degree of freedom & \\
\hline
\end{tabular}

\section{Mistake 4: Misunderstanding between Confirmatory and Exploratory Research}

While PLS-PM has been frequently used across research fields, but there are not many previous studies clearly explain the distinction between confirmatory and exploratory research. Many scholars claimed their study using PLS-PM because it works well with both confirmatory and exploratory research. It is important to know that confirmatory and exploratory research is different and have their own assumptions that need to be fulfilled. As a matter of fact, Ioannidis (2005) pointed out that most research findings are false. Thus, wrong results can lead to the wrong conclusion and eventually impacted the decisions. 
According to Wagenmakers et al. (2012), sciences and social sciences can be bad in many ways, such as faulty logic, flawed design, and misuse of statistical analysis. The erroneous statistical method has gained increasing recently in management research, as explicitly addressed by Guide \& Ketokivi (2015). Confirmatory theory proceeds from a priori hypotheses concerning some topic of interest (Jaeger \& Halliday, 1998) to test those hypotheses. Most research programs rely on inductive to prove the alternative hypothesis can be true. For many instances, research has shown that applied researchers interest in seeking confirmation rather than exploration (Nickerson, 1998). In other words, it can help the researchers to gain some confidence in the validity of those hypotheses.

In contrast, the exploratory research using beta error (type II error rate) indicates that there is no significant effect even though the effect actually existed in the true population (Willaby et al., 2015; Rönkko \& Evermann, 2013). Thus, exploratory research can be used to generate a hypothesis rather than testing the hypothesis. It should be noted that exploration is usually used to gain new insight from which new hypotheses might be developed (James \& McCullosh, 1985). It is fruitful for prediction purposes or examining the potential relationships between constructs in a single model. Though Rigdon (2014) pointed out that the nature of the confirmation model can be changed if the researchers use different established theories in a single model, it should be noted that the measured item remains the same. It means that the idea to claim the model is in exploratory research not achieved as the original items are used to assess the construct (measurement model).

Henseler (2017) contemplated that the characteristics of the construct can determine the character of the research design. Accordingly, any factors that describe the behavioral construct should be examined with CBSEM (confirmatory method), while design-construct should be tested with PLS-PM (exploratory method). These distinctions could help the applied researchers to understand confirmation and exploration better, as summarized in table 5 . 
Table 5 Different between Confirmatory and Exploratory Research

\begin{tabular}{|c|c|}
\hline CONFIRMATORY & EXPLORATORY \\
\hline $\begin{array}{l}\text { Replicating an established theory into a } \\
\text { new domain } \\
\text { - Confirming a pre-specified } \\
\text { relationship }\end{array}$ & $\begin{array}{l}\text { Develop a new model based on lack of } \\
\text { evidence or fact } \\
\text { - Connecting ideas to understand cause- } \\
\text { effect }\end{array}$ \\
\hline $\begin{array}{l}\text { For estimating purpose } \\
\text { Statistically significant results } \\
\text { Definitive answers to hypotheses }\end{array}$ & $\begin{array}{l}\text { For prediction purpose } \\
\text { Potential relationships } \\
\text { Novel relevant questions }\end{array}$ \\
\hline $\begin{array}{l}\text { For theory-driven } \\
\text { Hypotheses testing methods } \\
\text { Highest accuracy numerical models }\end{array}$ & For data-driven \\
\hline $\begin{array}{l}\text { For theory testing } \\
\text { Testing a priori hypotheses } \\
\text { Maximizing the confidence in } \\
\text { conclusions }\end{array}$ & $\begin{array}{l}\text { For theory development (exploration } \\
\text { purpose) } \\
\text { Developing promising a posteriori } \\
\text { hypothesis } \\
\text { Designing efficient experiments } \\
\text { Reinforcing confirmed conclusion }\end{array}$ \\
\hline For the common factor model & For the composite factor model \\
\hline $\begin{array}{l}\text { Modified the existing theory by } \\
\text { included a new path or construct }\end{array}$ & $\begin{array}{l}\text { Entirely changing the measurement item } \\
\text { in existing theory }\end{array}$ \\
\hline Integrating theory & $\begin{array}{l}\text { Change the relationships between } \\
\text { construct from prior theories (reciprocal } \\
\text { relationships) }\end{array}$ \\
\hline $\begin{array}{l}\text { Behavioral construct (attribute and } \\
\text { attitudes) }\end{array}$ & $\begin{array}{l}\text { Design construct (designer design the } \\
\text { construct) }\end{array}$ \\
\hline $\begin{array}{l}\text { Example: } \\
\text { Customer Satisfaction, Customer } \\
\text { Loyalty, Trust, Distrust, Attitudinal, } \\
\text { Communication, Affective, Emotion, } \\
\text { Leadership, Performance }\end{array}$ & $\begin{array}{l}\text { Example: } \\
\text { Brand equity, Type of system, } \\
\text { Information source, Decision-making } \\
\text { perspective, Network structure, } \\
\text { Network capability, Technology, } \\
\text { Device, Location }\end{array}$ \\
\hline
\end{tabular}




\section{Mistake 5: Poor Factor Loadings}

One of the essential approaches in SEM method is determining the value of factor loading for each construct. In CBSEM, this method was known as Confirmatory Factor Analysis (CFA), whereas in PLS-PM, the method was recognized as Confirmatory Composite Analysis (CCA). Both methods are used to evaluating the measurement model, but the ways for estimating the model are different. The value of factor loading is allowed for the reflective construct to assist the applied researcher in identifying the measured item's suitability under construct.

According to Awang et al. (2015) and Afthanorhan et al. (2019), the minimum value of factor loading is 0.60 , although some other resources also accept the value of factor loading at least 0.50 . This practice partially similar to PLS-PM but much more convenient as not many fitness indexes were deployed. Hair et al. (2019) suggested that the acceptable item loading is 0.708 , but the researcher can consider another item loading between 0.40 and 0.70 as long as the AVE and CR are achieved. This reliability and validity are sensitive to the number of items per construct and the value of factor loading, as depicted in Table 6. It showed that the higher factor loading is, the higher value of AVE and CR are.

Nevertheless, many applied researchers move to PLS-PM because the loadings usually obtained larger than the value of factor loading from CBSEM. The AVE and $\mathrm{CR}$ can be achieved from this advantages as it is part of the measurement model assessment. It should be noted the value of item loading from CBSEM is considered as factor loading, whereas in PLS-PM, it was called composite loading. Thus, the researchers should be consistent with one method after knowing the character of the model. 
Table 6 Rule of Thumb for Factor Loadings and AVE and CR

\begin{tabular}{|l|l|l|l|l|}
\hline $\begin{array}{c}\text { Number of } \\
\text { Items }\end{array}$ & Factor Loading & \multicolumn{1}{|c|}{ AVE } & \multicolumn{1}{|c|}{ CR } & \multicolumn{1}{c|}{ Comment } \\
\hline \multirow{4}{*}{2} & 0.60 & 0.360 & 0.529 & $\begin{array}{l}\text { AVE and CR not } \\
\text { achieved }\end{array}$ \\
\cline { 2 - 5 } & 0.75 & 0.563 & 0.720 & AVE and CR achieved \\
\cline { 2 - 5 } & 0.90 & 0.810 & 0.895 & AVE and CR achieved \\
\hline \multirow{4}{*}{} & 0.60 & 0.360 & 0.692 & $\begin{array}{l}\text { AVE and CR not } \\
\text { achieved }\end{array}$ \\
\cline { 2 - 5 } & 0.75 & 0.563 & 0.837 & AVE and CR achieved \\
\cline { 2 - 5 } & 0.90 & 0.810 & 0.945 & AVE and CR achieved \\
\hline 6 & 0.60 & 0.360 & 0.771 & AVE not achieved \\
\cline { 2 - 5 } & 0.75 & 0.563 & 0.885 & AVE and CR achieved \\
\cline { 2 - 5 } & 0.90 & 0.810 & 0.962 & AVE and CR achieved \\
\hline \multirow{5}{*}{8} & 0.60 & 0.360 & 0.818 & AVE not achieved \\
\cline { 2 - 5 } & 0.75 & 0.563 & 0.911 & AVE and CR achieved \\
\cline { 2 - 5 } & 0.90 & 0.810 & 0.972 & AVE and CR achieved \\
\hline \multirow{5}{*}{10} & 0.60 & 0.360 & 0.849 & AVE not achieved \\
\cline { 2 - 5 } & 0.75 & 0.563 & 0.928 & AVE and CR achieved \\
\cline { 2 - 5 } & 0.90 & 0.810 & 0.977 & AVE and CR achieved \\
\hline
\end{tabular}

\section{CONCLUDING REMARKS}

PLS-PM and CB-SEM generate the parameter estimates differently and offer different settings for the applied researchers. There are times where we want to understand the behavior of the fitness index. There are also times when we really want to handle the non-normal data and small sample size. We can get different findings from different methods, not because one method is good and another one is bad, but those methods actually approach the data using different philosophies.

If you are a good researcher, you will know to make a decision when analyzing the data, and if you are not familiar with these concepts and arguments, then we would encourage you to read the research papers from "Organizational Research Methods," Structural Equation Modeling" journal and articles cited in the reference list. From here, the researchers can learn how the usefulness of PLS-PM and CB-SEM, then create a value judgment on which method is more relevant for your quantitative research analysis. 
For those of you that overuse PLS-PM in management research, be careful about moderating the hater's statements by justifying the choice to use PLS-PM. We also strongly encourage you to consider CB-SEM technique as it might be a better tool for some of your research projects (Asnawi et al., 2019). Be sure to understand the PLSPM and CB-SEM, then use them properly as both of them can complement each other in data analysis. There also have several prominent researchers have now acknowledged the value of PLS-PM technique. Evidently, many top-tier journals in the management field accept the use of PLS-PM technique, and an extension of PLS methods such as efficient PLS, consistent PLS, weighted PLS, and PLS prediction are now introduced to cater to the limitation of traditional PLS-PM. We believe this paper can stimulate the SEM users to respect PLS-PM and CB-SEM techniques to accept the variety of research methods.

\section{REFERENCES}

Afthanorhan, A., Awang, Z., Rashid, N., Foziah, H., \& Ghazali, P. (2019). Assessing the effects of service quality on customer satisfaction. Management Science Letters, 9(1), 13-24. https://doi.org/10.5267/j.ms1.2018.11.004

Afthanorhan, A., Awang, Z., Salleh, F., Ghazali, P., \& Rashid, N. (2018). The effect of product quality, medical price and staff skills on patient loyalty via cultural impact in medical tourism. Management Science Letters, 8(12), 1421-1424. https://doi.org/10.5267/j.ms1.2018.10.004

Aimran, A. N., Ahmad, S., Afthanorhan, A., \& Awang, Z. (2017a). The development of comparative bias index. In AIP Conference Proceedings (Vol. 1870, No. 1, p. 060008). AIP Publishing. https://doi.org/10.1063/1.4995935

AL-Mhasnah, A., Salleh, F., Afthanorhan, A., \& Ghazali, P. (2018). The relationship between services quality and customer satisfaction among Jordanian healthcare sector. Management Science Letters, 8(12), 1413-1420.

https://doi.org/10.5267/j.msl.2018.10.003

Aguirre-Urreta, M. I., \& Marakas, G. M. (2014). A rejoinder to rigdon et al (2014). Information Systems Research, 25(4), 785-788.

https://doi.org/10.1287/isre.2014.0545

Aguirre-Urreta, M. I., \& Rönkkö, M. (2018). Statistical inference with PLSc using bootstrap confidence intervals. MIS Quarterly, 42(3), 1001-1020. https://doi.org/10.25300/misq/2018/13587

Anderson, J. C., \& Gerbing, D. W. (1988). Structural equation modeling in practice: A review and recommended two-step approach. Psychological Bulletin, 103(3), 411-423. https://doi.org/10.1037/0033-2909.103.3.411 
Antonakis, J., Bendahan, S., Jacquart, P., \& Lalive, R. (2010). On making causal claims: A review and recommendations. The Leadership Quarterly, 21(6), 10861120. https://doi.org/10.1016/j.leaqua.2010.10.010

Asnawi, A., Awang, Z., Afthanorhan, A., Mohamad, M., \& Karim, F. (2019). The influence of hospital image and service quality on patients' satisfaction and loyalty. Management Science Letters, 9(6), 911-920.

https://doi.org/10.5267/j.ms1.2019.2.011

Awang, Z. (2015). SEM made simple: A gentle approach to learning Structural Equation Modeling. MPWS Rich Publication.

Aziz, M., Adnan, A., Afthanorhan, A., Foziah, H., Ishak, S., \& Rashid, N. (2019). The influence of employer value proposition in talent demand towards talent shortage in the Malaysian Islamic banking institutions: A SEM approach. Management Science Letters, 9(6), 843-850. https://doi.org/10.5267/j.ms1.2019.3.004

Bentler, P. M., \& Yuan, K. H. (1999). Structural equation modeling with small samples: Test statistics. Multivariate behavioral research, 34(2), 181-197. https://doi.org/10.1207/s15327906mb340203

Bollen, K. A. (1989). A new incremental fit index for general structural equation models. Sociological Methods \& Research, 17(3), 303-316. https://doi.org/10.1177/0049124189017003004

Bollen, K. A. (2011). Evaluating effect, composite, and causal indicators in structural equation models. Mis Quarterly, 35(2), 359-372. https://doi.org/10.2307/23044047

Bollen, K. A., \& Diamantopoulos, A. (2017). In defense of causal-formative indicators: A minority report. Psychological Methods, 22(3), 581. https://doi.org/10.1037/met0000056

Bollen, K. A., \& Noble, M. D. (2011). Structural equation models and the quantification of behavior. Proceedings of the National Academy of Sciences, 108(Supplement 3), 15639-15646. https://doi.org/10.1073/pnas.1010661108

Byrne, B. M. (2016). Structural equation modeling with AMOS: Basic concepts, applications, and programming. Routledge.

Chen, F., Bollen, K. A., Paxton, P., Curran, P. J., \& Kirby, J. B. (2001). Improper solutions in structural equation models: Causes, consequences, and strategies. Sociological Methods \& Research, 29(4), 468-508. https://doi.org/10.1177/0049124101029004003

Chin, W. W., \& Newsted, P. R. (1999). Structural equation modeling analysis with small samples using partial least squares. Statistical Strategies for Small Sample Research, 1(1), 307-341. 
Chin, W. W., Marcolin, B. L., \& Newsted, P. R. (2003). A partial least squares latent variable modeling approach for measuring interaction effects: Results from a Monte Carlo simulation study and an electronic-mail emotion/adoption study. Information Systems Research, 14(2), 189-217.

https://doi.org/10.1287/isre.14.2.189.16018

Chong, E. E., Nazim, A., \& Ahmad, S. B. (2014). A comparison between individual confirmatory factor analysis and pooled confirmatory factor analysis: An analysis of library service quality, a case study at a public university in Terengganu. International Journal of Engineering Science and Innovative Technology, 3(1), 110-116.

Dijkstra, T. K., \& Henseler, J. (2015). Consistent Partial Least Squares Path Modeling. MIS Quarterly, 39(2).

Dijkstra, T. K., \& Schermelleh-Engel, K. (2014). Consistent partial least squares for nonlinear structural equation models. Psychometrika, 79(4), 585-604. https://doi.org/10.1007/s11336-013-9370-0

Ding, L., Velicer, W. F., \& Harlow, L. L. (1995). Effects of estimation methods, number of indicators per factor, and improper solutions on structural equation modeling fit indices. Structural Equation Modeling: A Multidisciplinary Journal, 2(2), 119-143. https://doi.org/10.1080/10705519509540000

Embretson, S. E., \& Reise, S. P. (2013). Item response theory. Psychology Press.

Fan, X., Thompson, B., \& Wang, L. (1999). Effects of sample size, estimation methods, and model specification on structural equation modeling fit indexes. Structural Equation Modeling: A Multidisciplinary Journal, 6(1), 56-83. https://doi.org/10.1080/10705519909540119

Fornell, C., \& Bookstein, F. L. (1982). Two structural equation models: LISREL and PLS applied to consumer exit-voice theory. Journal of Marketing research, 440452. https://doi.org/10.2307/3151718

Goodhue, D. L., Lewis, W., \& Thompson, R. (2012). Comparing PLS to regression and LISREL: A response to Marcoulides, Chin, and Saunders. Mis Quarterly, 703-716. https://doi.org/10.2307/41703476

Goodhue, D., Lewis, W., \& Thompson, R. (2006, January). PLS, small sample size, and statistical power in MIS research. In System Sciences, 2006. HICSS'06. Proceedings of the 39th Annual Hawaii International Conference on (Vol. 8, pp. 202b-202b). IEEE. https://doi.org/10.1109/hicss.2006.381

Guide Jr, V. D. R., \& Ketokivi, M. (2015). Notes from the Editors: Redefining some methodological criteria for the journal. Journal of Operations Management, 37(1), v-viii. https://doi.org/10.1016/s0272-6963(15)00056-X 
Haenlein, M., \& Kaplan, A. M. (2004). A beginner's guide to partial least squares analysis. Understanding statistics, 3(4), 283-297.

https://doi.org/10.1207/s15328031us0304_4

Hair, J. F., Risher, J. J., Sarstedt, M., \& Ringle, C. M. (2019). When to use and how to report the results of PLS-SEM. European Business Review.

https://doi.org/10.1108/ebr-11-2018-0203

Hair Jr, J. F., Matthews, L. M., Matthews, R. L., \& Sarstedt, M. (2017). PLS-SEM or CB-SEM: Updated guidelines on which method to use. International Journal of Multivariate Data Analysis, 1(2), 107-123. https://doi.org/10.1504/ijmda.2017.087624

Henseler, J., Hubona, G., \& Ray, P. A. (2016). Using PLS path modeling in new technology research: Updated guidelines. Industrial Management \& Data Systems, 116(1), 2-20. https://doi.org/10.1108/imds-09-2015-0382

Henseler, J. (2017). Bridging design and behavioral research with variance-based structural equation modeling. Journal of Advertising, 46(1), 178-192. https://doi.org/10.1080/00913367.2017.1281780

Henseler, J., Ringle, C. M., \& Sarstedt, M. (2015). A new criterion for assessing discriminant validity in variance-based structural equation modeling. Journal of the Academy of Marketing Science, 43(1), 115-135.

https://doi.org/10.1007/s11747-014-0403-8

Herzog, W., \& Boomsma, A. (2009). Small-sample robust estimators of noncentralitybased and incremental model fit. Structural Equation Modeling, 16(1), 1-27. https://doi.org/10.1080/10705510802561279

Hoyle, R. H. (1995). Structural equation modeling: Concepts, issues, and applications. Sage.

Hwang, H., Takane, Y., \& Tenenhaus, A. (2015). An alternative estimation procedure for partial least squares path modeling. Behaviormetrika, 42(1), 63-78. https://doi.org/10.2333/bhmk.42.63

Ioannidis, J. P. (2005). Why most published research findings are false. PLoS Medicine, 2(8), e124.

James, F. C., \& McCulloch, C. E. (1985). Data analysis and the design of experiments in ornithology. In Current Ornithology (pp. 1-63). Springer, Boston, MA. https://doi.org/10.1007/978-1-4613-2385-3_1

Jaeger, R. G., \& Halliday, T. R. (1998). On confirmatory versus exploratory research. Herpetologica, S64-S66.

Jöreskog, K. G., \& Sörbom, D. (1989). LISREL 7: A guide to the program and applications. Spss. 
Kline, R. B. (2015). Principles and practice of structural equation modeling. Guilford publications.

Lai, K., \& Kelley, K. (2011). Accuracy in parameter estimation for targeted effects in structural equation modeling: Sample size planning for narrow confidence intervals. Psychological Methods, 16(2), 127. https://doi.org/10.1037/a0021764

Landis, R. S., Beal, D. J., \& Tesluk, P. E. (2000). A comparison of approaches to forming composite measures in structural equation models. Organizational Research Methods, 3(2), 186-207. https://doi.org/10.1177/109442810032003

Loehlin, J. C. (1998). Latent variable models: An introduction to factor, path, and structural analysis. Lawrence Erlbaum Associates Publishers.

Lohmöller, J. B. (1989). Predictive vs. structural modeling: PLS vs. ML. In Latent Variable Path Modeling with Partial Least Squares (pp. 199-226). Physica, Heidelberg. https://doi.org/10.1007/978-3-642-52512-4 5

Marsh, H. W., Hau, K. T., Balla, J. R., \& Grayson, D. (1998). Is more ever too much? The number of indicators per factor in confirmatory factor analysis. Multivariate Behavioral Research, 33(2), 181-220.

https://doi.org/10.1207/s15327906mbr3302_1

Marsh, H. W., Wen, Z., \& Hau, K. T. (2004). Structural equation models of latent interactions: evaluation of alternative estimation strategies and indicator construction. Psychological Methods, 9(3), 275. https://doi.org/10.1037/1082989x.9.3.275

McIntosh, C. N., Edwards, J. R., \& Antonakis, J. (2014). Reflections on partial least squares path modeling. Organizational Research Methods, 17(2), 210-251. https://doi.org/10.1177/1094428114529165

Nickerson, R. S. (1998). Confirmation bias: A ubiquitous phenomenon in many guises. Review of General Psychology, 2(2), 175-220.

https://doi.org/10.1037/1089-2680.2.2.175

Polkinghorne, D. E. (2005). Language and meaning: Data collection in qualitative research. Journal of Counseling Psychology, 52(2), 137-145.

https://doi.org/10.1037/0022-0167.52.2.137

Ringle, C. M., Sarstedt, M., Mitchell, R., \& Gudergan, S. P. (2018). Partial least squares structural equation modeling in HRM research. The International Journal of Human Resource Management, 1-27.

Rigdon, E. E. (2014). Rethinking partial least squares path modeling: Breaking chains and forging ahead. Long Range Planning, 47(3), 161-167.

https://doi.org/10.1016/j.1rp.2014.02.003 
Rönkkö, M., \& Evermann, J. (2013). A critical examination of common beliefs about partial least squares path modeling. Organizational Research Methods, 16(3), 425-448. https://doi.org/10.1177/1094428112474693

Rönkkö, M., McIntosh, C. N., \& Antonakis, J. (2015). On the adoption of partial least squares in psychological research: Caveat emptor. Personality and Individual Differences, 87, 76-84. https://doi.org/10.1016/j.paid.2015.07.019

Rönkkö, M., McIntosh, C. N., Antonakis, J., \& Edwards, J. R. (2016). Partial least squares path modeling: Time for some serious second thoughts. Journal of Operations Management, 47, 9-27. https://doi.org/10.1016/j.jom.2016.05.002

Sarstedt, M., Hair, J. F., Ringle, C. M., Thiele, K. O., \& Gudergan, S. P. (2016). Estimation issues with PLS and CBSEM: Where the bias lies!. Journal of Business Research, 69(10), 3998-4010. https://doi.org/10.1016/j.jbusres.2016.06.00

Schuberth, F., Henseler, J., \& Dijkstra, T. K. (2018). Partial least squares path modeling using ordinal categorical indicators. Quality \& Quantity, 52(1), 9-35. https://doi.org/10.1007/s11135-016-0401-7

Takane, Y., \& Hwang, H. (2017). Comparisons among several consistent estimators of structural equation models. Behaviormetrika, 45(1), 157-188. https://doi.org/10.1007/s41237-017-0045-5

van der Linden, W. J., \& Hambleton, R. K. (Eds.). (2013). Handbook of modern item response theory. Springer Science \& Business Media.

Vandenberg, R. J. (2006). Introduction: Statistical and Methodological Myths and Urban Legends: Where, Pray Tell, Did They Get This Idea?. Organizational Research Methods, 9(2), 194-201. https://doi.org/10.1177/1094428105285506

Wagenmakers, E. J., Wetzels, R., Borsboom, D., van der Maas, H. L., \& Kievit, R. A. (2012). An agenda for purely confirmatory research. Perspectives on Psychological Science, 7(6), 632-638. https://doi.org/10.1177/1745691612463078

Willaby, H. W., Costa, D. S., Burns, B. D., MacCann, C., \& Roberts, R. D. (2015). Testing complex models with small sample sizes: A historical overview and empirical demonstration of what partial least squares (PLS) can offer differential psychology. Personality and Individual Differences, 84, 73-78.

https://doi.org/10.1016/j.paid.2014.09.008

Wold, H. (2004). Partial least squares. Encyclopedia of Statistical Sciences, 9.

Yuan, K. H., \& Bentler, P. M. (1998). Normal theory based test statistics in structural equation modelling. British Journal of Mathematical and Statistical Psychology, 51(2), 289-309. https://doi.org/10.1111/j.2044-8317.1998.tb00682.x 
Zainol, R, N., Zainol., A., F., Ibrahim, Y., Afthanorhan, A. (2019). Scaling up social innovation for sustainability: The roles of social enterprise capabilities.

Management Sciences Letters, 9(3), 457-466.

https://doi.org/10.5267/j.ms1.2018.12.005

Dr. Asyraf Afthanorhan (Corresponding author) is a lecturer at the Faculty of Business and Management, University of Sultan Zainal Abidin (UniSZA). He received PhD in Management Statistics at UniSZA in 2017. He also received a master of Science in Mathematical Sciences at the Faculty of Science and Technology, Universiti Malaysia Terengganu (UMT) in 2013. His main interest is Covariance Based Structural Equation Modeling, Partial Least Squares Path Modeling, Generalized Structured Component Analysis, Unobserved Heterogeneity Modelling and Scientific Literature Review. He is actively engaged in several Scopus journals, and most of his publications can be found in Researchgate, Google Scholar, and Scopus websites (Author ID: 5718433730). He also editor-in-chief of The Journal of Management Theory and Practice (JMTP).

Dr. Zainudin Awang is a professor at the Faculty of Faculty of Business and Management, Universiti Sultan Zainal Abidin (UniSZA), Kuala Terengganu. Before UniSZA, he was with UiTM since 1989. He was more than 25 years of experience lecturing in various statistical courses at the first degree as well as postgraduate level. Among the courses are regression analysis and structural equation modeling (SEM). He appointed as research consent in a few public and private organizations in the country.

Dr. Nazim Aimran is a Senior Lecturer at Faculty of Computer and Mathematical Sciences, UiTM. Before joining UiTM, he worked as a consultant at Frost \& Sullivan, a statistician at National Population and Family Development Board Malaysia, Central Bank of Malaysia, Human Resources Development Fund Malaysia and Ministry of Human Resources Malaysia. His expertise is in Multivariate Analysis, Structural Equation Modeling (SEM) and Research Methodology, besides experience in national-level studies related to population, well-being, housing, wages, and public opinion. 